of the net reproduction-rate to 1 , instead of the existing rate of $0 \cdot 75$, which this pamphlet recommends as a practical policy, would tend to stabilize the population at about three-quarters of its present figure.

The trend towards a rapid decline of population affects not only Great Britain, but also Norway, Sweden, France, Belgium, Switzerland and Austria, where populations will decline at about the same rate as Britain's will. Other countries, including Ireland, Germany, Italy, Russia, Japan, China and India, will show an increase by 1970 .

Among the causes of the population decline the pamphlet discusses (1) the enormously higher standard of living, leisure and comfort; (2) the great increase in mobility, which often makes the home into a place to be left as often as possible; (3) the almost universal literacy and widened outlook, due to reading in the local libraries and daily papers and to the radio; (4) the wide availability of contraceptives, which tend to affect the birth-rate in the groups of higher income and education; and (5) profound changes in our conceptions about religion, duty and social behaviour.

In Britain there is no spiritual significance of parenthood comparable to that which exists in India and China. Education stresses the importance of the individual, so that the child tends to ask what it can get out of life, rather than what it can give.

Among the remedies proposed by the Tory Reform Committee is the creation of a domestic service, which would make housework an attractive career. It also suggests that positive action should be taken in Parliament to bring this whole problem of population and family life more frankly before the people, to remove economic barriers to early marriage and to make two, three or four children an economic possibility in all classes, instead of a severe liability as they are at present. The alternatives against which the young married couples of the next few years can protect us if we enable them to do so are, the Committee thinks, decay through a progressively declining population, or immigration from countries with growing populations, including those of the East.

G. LAPAGE.

\section{POLLEN ANALYSIS AND THE MUSEUMS}

$\mathrm{H}$ A. HYDE, of the National Museum of Wales, has published an informative article on the technique, history and applications of pollen analysis (Museums J., Dec. 1944).

The study of atmospheric pollens in England began in 1867 when Charles Blackley, a Manchester medical practitioner, exposed to the air micro-slides treated with an adhesive, and found that the days when the slides showed most pollen grains coincided with those on which his hay-fever patients suffered worst.

In 1941 a detailed day-to-day census was begun at Cardiff, and the results obtained during 1942 (see "Studies in Atmospheric Pollen. I. A daily census of pollens at Cardiff, 1942". By H. A. Hyde and Dr. D. A. Williams. New Phyt., 43, 49; 1944) showed that the effective pollen season lasted from early March until late September, and (as previously discovered in the United States) presented three phases characterized by the pollens of trees, grasses and other herbs respectively. The applications of pollen research are numerous. At Cardiff the work is maintained chiefly for the purpose of assisting medical allergists in making their diagnosis; but in addition because it is of value in the pollen analysis of peat, in experiments on the hybridization of plants, and in meteorological work concerned with the movement of air currents. Again, pollen analysis has been employed-notably in Central Europe-in the determination of the source of origin of honey, and the author suggests that in the future bee-keeping and other departments of horticulture are likely to benefit from similar research. In this connexion he directs attention to the fact that the kinds of pollen collected by certain species of bees are already being investig. ated under official auspices.

Geological or archæological correlations are probably the most widely known applications of pollen analysis, but the work so far carried out does not yet provide a complete and independent time-scele for dating archæological finds. It has, nevertheless, made possible the reconstruction of the forest history of England and Wales since the close of the last Ice Age, and the working out of a number of correlations with human culture periods.

At the end of his paper the author suggests that "(pending the establishment of an institute of palynology ?)" at least the national museums should carry out fundamental pollen research, and that the larger regional museums might consider undertaking certain aspects of the work. In support of the desirability of this, he points out that certain public authorities in the United States carry out daily analyses of atmospheric pollens, and he is of the opinion that it will not be long before similar observa. tions will be required in Great Britain. Collaboration between museums and public health authorities (both often under the same municipal authority) would, therefore, be of mutual advantage.

\section{FORTHCOMING EVENTS}

\author{
Saturday, April 21
}

SOCIRTY OF INSTRUMRNT ThCHNOLOGY (at the London School of Tropical Medicine, Keppel Street, Gower Street, London, W.C.1) at 11 a.m.

Association For ScIENTIFIo PHotograpHy (at Caxton Hall, Westminster, London, S.W.1), at 2.30 p.m.-Mr. E. Mackie: "A Consideration of the Requirements for Micrography and Cinemicrography Apparatus".

\section{Monday, April 23}

ROYal Socierty of ARTs (at John Adam Street, Adelphi, London, W.C.2), at 1.45 p.m. Sir Frank Smith, G.C.B., G.B.E., F.R.S. "Chemicals from Petroleum" (Cantor Lectures, 2).

ROYAL GEOGRAPHICAX SOCIETY (at Kensington Gore, South Kensington, London, S.W.7), at 5 p.m.- "Fnthronement of the Dalai Lama and Journeys in Bhutan" (Kodachrome Films by Sir Basil Gould, with Commentary by Colonel F. M. Bailey).

INSTITUTTON OF ELEOTRICAL ENGINEERS (at Savoy Place, Victoria Embankment, London, W.C.2), at 5.30 p.m.-Discussion of "Electrical

association of Austrian Engineers, Chemists and Scientific ASSOCIATION OF AUSTRIAN ENGINFERS, CHFMISTS AND SCIENTIFIC
WORKERS IN GREAT BRITAIN (PHARMICCEUTYOAI GROOP) (at the WORKRRS IN GREAT BRITAIN (PHARMACEUTYOAL GROOP) (at the
Austrian Centre, 69 Eton Avenue, Hampstead, London, N.W.3), at 7.30 p.m.- "Some Interesting Facts on Sex-determining Compounds" (based on work by Mr. R. Kuhn).

\section{Tuesday, April 24}

Shemrimid Mmtallumgical Assooration (at 198 West Street, Sheffield 1), at 6.30 p.m.-Dr. H. O'Neill: "The Signiflcance of the Mechanical Test Properties of Metals".

QUERRTT Mrcroscopical CuUB (at the Royal Society, Burlington House, Piccadilly, London, W.1), at 7.30 p.m.-Mr. A. C. G. Best "Celloidin Embedding and Sectioning".

\section{Wednesday, April 25}

SoOIETy OF CHRMical INDUSTRY (FOOD GROUP) (at the Chemical Society, Burlington House, Piccadilly, London, W.1), at 2.30 p.m.Annual General Meeting; Mr. A. N. Duckham: "Food Management and the Chemist".

SOCIRTY Of Chemical INDUSTRY (NEWOASTLE-UPON-TYNE ShOTION) (in the King's Hall, King's College, Newcastle-upon-Tyne), at 5 p.m. orial Lecture). 